\title{
Multiple lifestyle behaviours and mortality, findings from a large population-based Norwegian cohort study - The HUNT Study
}

(1) CrossMark

Steinar Krokstad ${ }^{1,2^{*}+}$, Ding Ding ${ }^{3,4 \dagger}$, Anne C. Grunseit ${ }^{3}$, Erik R. Sund ${ }^{1}$, Turid Lingaas Holmen ${ }^{1}$, Vegar Rangul ${ }^{1}$ and Adrian Bauman ${ }^{1,3}$

\begin{abstract}
Background: Lifestyle risk behaviours are responsible for a large proportion of disease burden and premature mortality worldwide. Risk behaviours tend to cluster in populations. We developed a new lifestyle risk index by including emerging risk factors (sleep, sitting time, and social participation) and examine unique risk combinations and their associations with all-cause and cardio-metabolic mortality.

Methods: Data are from a large population-based cohort study in a Norway, the Nord-Trøndelag Health Study (HUNT), with an average follow-up time of 14.1 years. Baseline data from 1995-97 were linked to the Norwegian Causes of Death Registry. The analytic sample comprised 36911 adults aged 20-69 years. Cox regression models were first fitted for seven risk factors (poor diet, excessive alcohol consumption, current smoking, physical inactivity, excessive sitting, too much/too little sleep, and poor social participation) separately and then adjusted for sociodemographic covariates. Based on these results, a lifestyle risk index was developed. Finally, we explored common combinations of the risk factors in relation to all-cause and cardio-metabolic mortality outcomes.
\end{abstract}

Results: All single risk factors, except for diet, were significantly associated with both mortality outcomes, and were therefore selected to form a lifestyle risk index. Risk of mortality increased as the index score increased. The hazard ratio for all-cause mortality increased from 1.37 (1.15-1.62) to 6.15 (3.56-10.63) as the number of index risk factors increased from one to six respectively. Among the most common risk factor combinations the association with mortality was particularly strong when smoking and/or social participation were included.

Conclusions: This study adds to previous research on multiple risk behaviours by incorporating emerging risk factors. Findings regarding social participation and prolonged sitting suggest new components of healthy lifestyles and potential new directions for population health interventions.

Keywords: Lifestyle behaviour, Risk factors, All-cause mortality, Cardiovascular disease, Metabolic disease, Cohort study

\section{Background}

Lifestyle risk behaviours, such as poor diet, smoking, and physical inactivity are responsible for a large proportion of disease burden and premature mortality worldwide [1, 2]. Risk behaviours tend to co-occur and cluster in

\footnotetext{
* Correspondence: steinar.krokstad@ntnu.no

${ }^{\dagger}$ Equal contributors

${ }^{1}$ HUNT Research Centre, Department of Public Health and General Practice,

Norwegian University of Science and Technology, Forskningsveien 2, 7600 Levanger, Norway

${ }^{2}$ Levanger Hospital, Nord-Trøndelag Hospital Trust, Levanger, Norway

Full list of author information is available at the end of the article
}

populations [3], suggesting the need for an integrated multiple behaviour approach. Previous studies have applied an index (i.e., a weighted or unweight sum of risk factors) as an indicator for overall or cumulative lifestyle risk [4]. A meta-analysis by Loef et al. found that those with at least four health behaviours had a $66 \%$ reduced risk of all-cause mortality [5]. In addition to all-cause mortality [6], lifestyle indexes have shown clear relationships with cancer risk [7-12], cardiovascular incidence and mortality [12-16] and diabetes [17]. A recent study showed that combinations of risk factors had synergistic 
effects on all-cause mortality, where some risk combinations were more harmful than others [4].

To date, most studies include smoking, at-risk alcohol consumption, physical inactivity, and poor diet as key components of lifestyle indexes [5]. With evidence accumulating on new risk factors, lifestyle indexes may be revisited and updated to reflect the current evidence base [16]. Emergent risk factors include prolonged sitting time which may be a risk factor for dysmetabolic indicators [18, 19] and all-cause mortality [20]. Research has also shown that insufficient or excessive amounts of sleep are associated with increased risk of chronic disease and mortality [21-23]. In addition, measures of social connectivity and social capital appear to be related to population health, contributing beyond that attributable to traditional risk factors [24-27]. For example, a recent study identified the association between social relations, social support, and chronic systemic inflammation, as a precursor of major chronic diseases and biomarkers of ageing [28]. These three emergent behaviours, namely, prolonged sitting, sleep duration, and social participation could be examined in addition to the existing lifestyle risk factors in new approaches to profiling 'lifestyle risk'.

\section{Methods}

The aim of this study was to extend previous work around lifestyle indexes in a prospective population based cohort study in Norway. Specifically, to determine whether sleep, sitting time and social participation would contribute to the concept of 'lifestyle risk', we examined their associations with all-cause and cardio-metabolic mortality as 1) single risk factors, 2) components of a new lifestyle risk index, and 3) in unique combinations with other lifestyle risk behaviours.

\section{Sampling and procedures}

The Nord-Trøndelag Health Study (HUNT) is a large population-based cohort study conducted in the Nord-Trøndelag County located in central Norway (www.ntnu.edu/hunt) [29]. To date, three waves of data collection have been conducted: HUNT1 (1984-1986), HUNT2 (1995-1997), and HUNT3 (2006-2008). The current study is based on HUNT2 [30]. All inhabitants of the county aged 20 years and above were invited to participate and $70 \%$ joined the study by completing self-administered questionnaires on lifestyles and health ( $n=78976$, participation rate $70 \%$ ).

After excluding those aged 70 and above $(n=24730)$ because they completed a different questionnaire which did not include all questions on lifestyle behaviours, and those with missing value on at least one lifestyle behaviour question ( $n=17516$ ), our final analytical sample was restricted to 19556 men and 17355 women aged between 20 and 69 years at baseline.

\section{Measures \\ Lifestyle behaviours}

Smoking Participants were asked whether they smoked cigarettes/cigar/cigarillo/pipe on a daily basis, and those who were current smokers were defined as 'at risk'.

Alcohol consumption Alcohol risk was assessed using the Cut-Annoyed-Guilty-Eyeopener (CAGE) questionnaire (one point each for answering 'yes' to ever: 'feeling the need to cut down on drinking'; 'annoyed by people criticizing drinking'; 'feeling guilty about drinking'; and 'needed a drink first thing in the morning as an eyeopener')[31]. The CAGE questionnaire has been extensively used and validated as a screening instrument for alcohol-related problems [32], and those who scored $\geq 2$ were defined as 'at risk'.

Diet Dietary risk was assessed from one question indicating use of butter/hard margarine for cooking as compared with vegetable oil, oil blend, and soft margarine (as recommended by the health authorities). Participants using any of the former were classified as 'at risk'. As only limited dietary questions were included in this survey, we used the current question as an indicator for dietary choice.

Physical activity Physical activity was derived from two items measuring leisure-time 'light' activity (no sweating or being out of breath) and 'hard' activity (sweating/out of breath) during an average week in the last year. The 'hard' physical activity question has been found to be a valid measure of vigorous intensity physical activity [33, 34], and the 'light' physical activity question has moderate correlation with the International physical activity questionnaire (IPAQ) measure of moderate-intensity physical activity [33]. Being 'at risk' was defined as less than three hours/ week of light and no hard activity or less than one hour per week of light and less than one hour per week of hard activity per week [35]. Missing values for one form of physical activity (but not both) ( $n=16595)$ were given zero for that physical activity type.

Sedentary behaviour Sedentary behaviour was assessed using the single question 'how many hours do you usually spend sitting down during a $24 \mathrm{~h}$ period?' Participants were prompted to recall sitting at work, mealtimes, watching TV, sitting in a car, etc. We classified sitting for more than seven hours per day as 'at risk', based on a recent meta-analysis on sitting and all-cause mortality [36].

Sleep Sleep time included both night time sleep and naps and we defined six hours/day or less ('short 
duration') and $10 \mathrm{~h}$ /day or more ('long duration') as 'at risk', based on recent meta-analytic evidence [37, 38].

\section{Social participation}

Social participation was measured using a single itemquestion 'How often do you usually participate in social activities such as a sewing club, athletic club, political association, religious or other groups?' Those reporting 'never, or only a few times a year' were classified as 'at-risk' [27, 39].

\section{Mortality outcomes}

The study data were linked to the Norwegian Causes of Death Registry by Statistics Norway, based on the unique Norwegian 'personal identity number', which is assigned to every Norwegian citizen at birth. Death information was obtained from 1 January 1994 to 31 December 2010, with endpoints as mortality from all causes and from cardio-metabolic diseases (CMD). Causes of death were coded based on the International Classification of Disease (ICD) and we identified deaths from CMD (diseases of the circulatory system, and endocrine, nutritional and metabolic diseases) using ICD-9 (codes 240-279, 390-459) for deaths occurring up to 1996 and ICD-10 (codes E10E16, E65-E68, I00-I99) for deaths from 1996 onwards. Each participant contributed person years from the date of participation in the survey until the date of death or until the end of follow-up, whichever came first.

\section{Statistical analysis}

The relationships between the seven lifestyle risk behaviours and mortality were analysed using Cox proportional hazards models for both all-cause and CMD mortality. Age was the time scale used with age at screening as the entry time and age at death/censoring as the exit time. Age rather than time-on-study was used as the time scale, as previous simulation studies have shown that the former method yields more accurate results because risk estimates are calculated on people of the same age [40]. Cox regression models were run firstly with each risk factor alone and then adjusted for sex, highest level of education attained and marital status as covariates. Competing risks models were used for CMD mortality to account for those dying of other causes [41]. Results are presented as adjusted hazard ratios (HR) for all-cause mortality and subhazard ratio (SHR) for CMD mortality.

Secondly, a lifestyle risk index was created by summing risk behaviours that were significant from the analysis described above. Poor diet was excluded from the index as none of the bivariate analyses demonstrated a significant association with all-cause or CMD mortality.
All individual risk behaviours were coded 1 as 'at risk', and 0 as 'not at risk'; therefore the overall index score ranged 0 to 6 . Two Cox-regression models adjusted for sex, education and marital status were then run to examine the association between lifestyle risk index and all-cause and CMD mortality as described above.

Finally, we explored the implications for mortality of all 64 possible mutually exclusive combinations of the six components of the lifestyle risk index. We present and focus our interpretation on the most common combinations (occurring in $>3 \%$ of the sample) due to the small cell sizes and wide confidence intervals in less common combinations. Based on Cox proportional hazards models, we calculated the hazard ratio and subhazard ratio for each combination compared with those without any risk factor [42]. All analyses were conducted using Stata 13.1 (College Station, TX, Stata Corporation) and a threshold of 0.05 used for statistical significance.

\section{Results}

We linked 11766 records of death, of which 5140 were caused by CMD, to 78975 participant records from HUNT2 (excluding two participants for whom dates of death preceded their date of screening). The final sample for analysis included 36911 participants who had complete data for all risk factors. They were aged between 20 and 69 at baseline, and 2220 had died (683 deaths caused by CMD) prior to 31 December 2010. The study sample had an average follow-up of 14.1 years for a total of 522182 person years. At baseline, the average age of the participants was 43.6 years $(\mathrm{SD}=12.9), 53 \%$ were women, $11.4 \%$ had an educational level of university qualifying exam/ junior college, and $24.7 \%$ had university/postsecondary education. Sixty-two percent of the sample was married or in a de-facto relationship.

The data shown in Table 1 suggests that the more prevalent risk factors were poor diet (63\%), low social participation $(41.4 \%)$, physical inactivity $(40.1 \%)$ and prolonged sitting $(38.7 \%)$, with fewer at risk from other factors $(13.8 \%$ reported too little/too much sleep and $8.3 \%$ alcohol risk). All risk factors yielded highly significant $(p<0.001)$ differences across all of the demographic variables with the exception of poor diet by marital status $(p=0.527)$, probably due to the large sample size in the case where difference were small (i.e., less than 3\%). However, a number of differences were larger and worthy of note. Overall, men had higher risk for alcohol-related problems, low social participation, and lower risk for physical inactivity than women. Those who were older had lower risk for smoking, alcohol, and excessive sitting but had higher risk for physical inactivity, and short/long sleep durations. Those with university education had lower risk for poor diet, smoking, physical inactivity, and low social participation, 
Table 1 Baseline demographic characteristics of adult respondents in the Nord-Trøndelag Health Study (the HUNT Study), Norway (1995-1997)

\begin{tabular}{|c|c|c|c|c|c|c|c|c|c|}
\hline \multirow[t]{2}{*}{ Characteristics $^{a}$} & & \multirow[b]{2}{*}{$n$} & \multirow{2}{*}{$\begin{array}{l}\text { Poor } \\
\text { Diet } \\
(\%)^{a}\end{array}$} & \multirow{2}{*}{$\begin{array}{l}\text { Alcohol } \\
\text { risk } \\
(\%)\end{array}$} & \multirow{2}{*}{$\begin{array}{l}\text { Currently } \\
\text { Smoking } \\
\text { (\%) }\end{array}$} & \multirow{2}{*}{$\begin{array}{l}\text { Physical } \\
\text { inactivity } \\
(\%)\end{array}$} & \multirow{2}{*}{$\begin{array}{l}\text { Excessive } \\
\text { Sitting } \\
\text { (\%) }\end{array}$} & \multirow{2}{*}{$\begin{array}{l}\text { Sleep } \\
\text { risk } \\
(\%)\end{array}$} & \multirow{2}{*}{$\begin{array}{l}\text { Poor social } \\
\text { participation } \\
(\%)\end{array}$} \\
\hline & & & & & & & & & \\
\hline \multirow[t]{2}{*}{ Sex } & Female & 19556 & 61.1 & 3.1 & 33.9 & 42.4 & 34.1 & 13.1 & 36.9 \\
\hline & Male & 17355 & 65.1 & 14.2 & 30.4 & 37.5 & 43.7 & 14.5 & 46.5 \\
\hline \multirow[t]{4}{*}{ Age } & $20-35$ & 10697 & 64.6 & 9.5 & 29.6 & 31.4 & 39.1 & 15.4 & 40.7 \\
\hline & $>35-50$ & 14217 & 62.9 & 9.1 & 36.5 & 41.4 & 41.1 & 11.8 & 36.8 \\
\hline & $>50-65$ & 9866 & 61.5 & 6.8 & 30.1 & 46.8 & 37.0 & 13.3 & 47.1 \\
\hline & $>65-69$ & 2131 & 62.7 & 4.7 & 26.3 & 44.3 & 27.6 & 21.2 & 49.5 \\
\hline \multirow[t]{5}{*}{ Educational attainment } & Primary school & 9392 & 64.1 & 7.3 & 40.4 & 52.6 & 27.4 & 17.0 & 54.3 \\
\hline & High school & 13768 & 66.4 & 9.2 & 36.4 & 41.8 & 34.2 & 14.1 & 41.9 \\
\hline & Junior college & 4203 & 64.0 & 8.6 & 27.3 & 31.0 & 46.7 & 13.4 & 34.6 \\
\hline & University/post-secondary & 9126 & 56.3 & 8.0 & 19.8 & 28.5 & 53.3 & 9.9 & 30.0 \\
\hline & Missing & 422 & 60.7 & 6.4 & 33.2 & 46.9 & 36.3 & 21.1 & 53.3 \\
\hline \multirow[t]{3}{*}{ Marital status } & Single/divorced/separated/windowed & 14113 & 63.3 & 11.4 & 35.9 & 36.4 & 40.2 & 16.2 & 47.3 \\
\hline & Married/De-facto & 22708 & 62.8 & 6.4 & 29.9 & 42.4 & 37.7 & 12.3 & 37.7 \\
\hline & Missing & 90 & 60.0 & 6.7 & 30.0 & 41.1 & 47.8 & 14.4 & 50.0 \\
\hline Total & All respondents & 36911 & 63.0 & 8.3 & 32.2 & 40.1 & 38.7 & 13.8 & 41.4 \\
\hline
\end{tabular}

Poor diet: measured using a dietary indicator (i.e., using butter/hard margarine for cooking); Alcohol risk was measured using the CAGE questionnaire; current smoker; physical inactivity was defined as $<3 \mathrm{~h} /$ week moderate PA and no vigorous PA OR $<1 \mathrm{~h} /$ week moderate PA and $<1 \mathrm{~h} /$ week vigorous PA/week; Excessive siting was defined as sitting for more than $7 \mathrm{~h}$ per day; sleep risk was defined as sleeping too little ( $\leq 6 \mathrm{~h} /$ day) or too much ( $\geq 10 \mathrm{~h} /$ day); poor social participation was defined as 'never or only a few times per year' of participation in social clubs, associations or groups

but were at higher risk for excessive sitting than those without a university education. Those who were married or in a de-facto relationship were at lower risk for alcoholrelated problems, smoking, and poor social participation.

Table 2 presents the unadjusted and adjusted association between each individual risk factor and all-cause and CMD-mortality. All risk behaviours, except for poor diet, were significantly associated with both mortality outcomes in unadjusted models, and remained significant but slightly attenuated in adjusted models. Based on the adjusted models, smoking and alcohol risk had the strongest associations with all-cause mortality, and smoking and physical inactivity had the strongest associations with CMD mortality.

Due to the lack of association between dietary risk and mortality outcomes, we summed only the remaining six risk behaviours to create a lifestyle risk index. As Table 3 indicates, there was a dose-response relationship between the index score and mortality, and the association was particularly strong with CMD mortality. Those with more than three risk conditions showed a three to sixfold increase in the risk of all cause or CMD deaths, irrespective of which risk factors were present.

Table 4 shows the 12 most prevalent combinations of risk behaviours among the participants. Compared with those without any risk behaviour, which amounted to just over $14 \%$ of the sample, the most common risk profiles were 'excessive sitting only' (9.6\%, no significant association with mortality), 'physical inactivity only' (7.5\%, significantly associated with CMD mortality, adjusted HR $=1.68)$, 'poor social participation' $(6.8 \%$, significantly associated with all-cause mortality, adjusted $\mathrm{HR}=1.42$ and CMD-mortality, adjusted SHR 1.57), and 'physical inactivity and poor social participation' $(5.4 \%$ no significant association with mortality). The largest effect size was for the combination was for smoking, physical inactivity and poor social participation, increasing the risk of all-cause mortality by a factor of 2.87 and CMD-mortality by 3.13 when compared with having no risk factors and adjusting for demographic characteristics. Smoking either alone or in combination was implicated in the four risk factor combinations yielding the highest hazards for all-cause mortality, and in three of the top four for CMD-mortality.

\section{Discussion}

Lifestyle risk indexes can be used as parsimonious indicators of a person's overall or cumulative risk for non-communicable chronic disease and mortality. We examined whether sleep, sitting time and social participation could be usefully added to existing life style indexes, and our results showed these risk factors captured additional risk of death in a population sample of Norwegian adults. All risk behaviours except for the diet indicator 
Table 2 Individual lifestyle risk behaviour associated with all-cause and cardio-metabolic disease (CMD) mortality in the NordTrøndelag Health Study (the HUNT Study), Norway (1995-1997 to 2010, $n=36$ 911)

\begin{tabular}{|c|c|c|c|c|c|c|c|c|}
\hline \multirow{2}{*}{ Risk Factor ${ }^{\mathrm{a}}$} & & \multicolumn{4}{|c|}{ All-cause mortality } & \multicolumn{3}{|c|}{ CMD mortality } \\
\hline & & $\bar{n}$ & Total died & $\begin{array}{l}\text { Unadjusted HR } \\
(95 \% \mathrm{Cl})\end{array}$ & $\begin{array}{l}\text { Adjusted } \mathrm{HR}^{\mathrm{b}} \\
(95 \% \mathrm{Cl})\end{array}$ & Total died & $\begin{array}{l}\text { Unadjusted SHR } \\
(95 \% \mathrm{Cl})\end{array}$ & $\begin{array}{l}\text { Adjusted SHR } \\
(95 \% \text { Cl) }\end{array}$ \\
\hline \multirow[t]{2}{*}{ Diet } & Not at risk & 13659 & 848 & 1 & 1 & 249 & 1 & 1 \\
\hline & At risk & 23252 & 1,372 & $0.99(0.91-1.08)$ & $0.96(0.88-1.05)$ & 434 & $1.07(0.92-1.25)$ & $1.04(0.89-1.21)$ \\
\hline \multirow[t]{2}{*}{ Alcohol consumption } & Not at risk & 33837 & 1,981 & 1 & 1 & 617 & 1 & 1 \\
\hline & At risk & 3074 & 239 & $1.84(1.61-2.10)$ & $1.47(1.28-1.68)$ & 66 & $1.59(1.24-2.06)$ & $1.12(0.86-1.45)$ \\
\hline \multirow[t]{2}{*}{ Smoking } & Not at risk & 25016 & 1,204 & 1 & 1 & 387 & 1 & 1 \\
\hline & At risk & 11895 & 1,016 & $2.16(1.99-2.35)$ & $2.06(1.89-2.24)$ & 296 & $1.86(1.60-2.16)$ & $1.71(1.47-1.99)$ \\
\hline \multirow[t]{2}{*}{ Physical activity } & Not at risk & 22113 & 1,143 & 1 & 1 & 335 & 1 & 1 \\
\hline & At risk & 14798 & 1,077 & 1.19 (1.09-1.29) & $1.23(1.13-1.34)$ & 348 & $1.27(1.09-1.47)$ & $1.35(1.16-1.58)$ \\
\hline \multirow[t]{2}{*}{ Sitting time } & Not at risk & 22646 & 1,389 & 1 & 1 & 408 & 1 & 1 \\
\hline & At risk & 14265 & 831 & $1.18(1.08-1.28)$ & $1.16(1.06-1.27)$ & 275 & $1.35(1.16-1.58)$ & $1.30(1.11-1.52)$ \\
\hline \multirow[t]{2}{*}{ Sleep Duration } & Not at risk & 31821 & 1,785 & 1 & 1 & 535 & 1 & 1 \\
\hline & At risk & 5090 & 435 & $1.35(1.22-1.50)$ & $1.32(1.19-1.47)$ & 148 & $1.48(1.23-1.78)$ & $1.44(1.19-1.73)$ \\
\hline \multirow[t]{2}{*}{ Social participation } & Not at risk & 21631 & 1,015 & 1 & 1 & 294 & 1 & 1 \\
\hline & At risk & 15280 & 1,205 & $1.41(1.30-1.53)$ & $1.25(1.15-1.37)$ & 389 & $1.48(1.28-1.73)$ & $1.24(1.06-1.45)$ \\
\hline
\end{tabular}

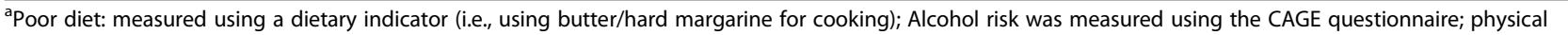
inactivity was defined as $<3 \mathrm{~h} /$ week moderate PA and no vigorous PA OR $<1 \mathrm{~h} /$ week moderate PA and $<1 \mathrm{~h} /$ week vigorous PA/week; Excessive siting was defined as sitting for more than $7 \mathrm{~h}$ per day; sleep risk was defined as sleeping too little ( $\leq 6 \mathrm{~h} /$ day) or too much ( $\geq 10 \mathrm{~h} /$ day); poor social participation was defined as 'never or only a few times per year' of participation in social clubs, associations or groups. ${ }^{\text {b}}$ Adjusted Hazard Ratio (HR) and subhazardratio (SHR): Adjusted for sex, educational attainment, marital status

were significantly associated with both mortality outcomes even when adjusted for socio-demographic characteristics. Moreover, clusters of risk behaviours prevalent in the sample demonstrated the incremental effect on mortality as the total number increased in any combination, but particularly when including smoking and/or social participation.

The twelve most prevalent patterns of risk factor combinations shown in Table 4, described just over $70 \%$ of the sample. Prolonged sitting in isolation was not a significant risk factor, and physical inactivity by itself, was a risk factor for CMD only. When in combination together however, they represented $4.4 \%$ of the sample, and showed substantial increased risk for all cause and particularly CMD deaths. This finding is similar to that report in a recent study conducted in Australia [4]. Additionally, physical inactivity was implicated in half of the top twelve risk combinations in terms of prevalence signalling that a change in this specific risk factor would represent change in the mortality risk in over a quarter of the population.

Social participation and smoking, by themselves, or in combination with other risks, were strongly associated with all-cause and CMD deaths. The combinations of risk factors show that some are synergistic. Although

Table 3 Lifestyle risk index ${ }^{a}$ associated with all-cause and cardio-metabolic disease (CMD) mortality in the Nord-Trøndelag Health Study (the HUNT Study), Norway (1995-1997 to 2012, $n=37$ 785)

\begin{tabular}{|c|c|c|c|c|c|}
\hline & \multicolumn{3}{|c|}{ All-cause mortality } & \multicolumn{2}{|c|}{ CMD mortality } \\
\hline & $\bar{n}$ & Deaths & Adjusted $\mathrm{HR}^{\mathrm{b}}(95 \% \mathrm{Cl})$ & Deaths & Adjusted SHR ${ }^{\mathrm{b}}(95 \% \mathrm{Cl})$ \\
\hline No risk behaviour & 5312 & 170 & 1 & 39 & 1 \\
\hline One & 11703 & 582 & $1.37(1.15-1.62)$ & 180 & $1.75(1.24-2.48)$ \\
\hline Two & 11364 & 673 & $1.55(1.31-1.84)$ & 210 & $1.94(1.38-2.73)$ \\
\hline Three & 6557 & 566 & $2.26(1.91-2.69)$ & 184 & $2.80(1.97-3.96)$ \\
\hline Four & 2312 & 260 & $3.16(2.60-3.85)$ & 84 & $3.66(2.49-5.37)$ \\
\hline Five & 480 & 72 & $4.26(3.22-5.62)$ & 28 & $5.28(3.18-8.77)$ \\
\hline Six & 57 & 14 & $6.15(3.56-10.63)$ & 2 & $2.23(0.50-9.92)$ \\
\hline
\end{tabular}

a Lifestyle risk index was a sum of the following six risk behaviours: at-risk alcohol consumption, currently smoking, physical inactivity, excessive sitting, sleep too little/much, and poor social participation

${ }^{\mathrm{b}} H R$, Hazard ratio and SHR, subhazardratio: Adjusted for sex, educational attainment and marital status 
Table 4 The most common 12 combinations of individual risk behaviours associated with all-cause and cardio-metabolic disease (CMD) mortality in the Nord-Trøndelag Health Study (HUNT), Norway (1995-1997 to 2012, n= 37 785)

\begin{tabular}{|c|c|c|c|c|c|c|c|c|c|c|c|}
\hline \multirow[t]{2}{*}{ Combinations } & \multirow[t]{2}{*}{ Alcohol } & \multirow[t]{2}{*}{ Smoking } & \multirow{2}{*}{$\begin{array}{l}\text { Physical } \\
\text { inactivity }\end{array}$} & \multirow[t]{2}{*}{ Sitting } & \multirow[t]{2}{*}{ Sleep } & \multirow{2}{*}{$\begin{array}{l}\text { Social } \\
\text { participation }\end{array}$} & \multicolumn{3}{|c|}{ All-cause mortality } & \multicolumn{2}{|c|}{ CMD mortality } \\
\hline & & & & & & & Prevalence & Deaths & $\begin{array}{l}\text { Adjusted }{ }^{a} \mathrm{HR} \\
(95 \% \mathrm{Cl})\end{array}$ & Deaths & Adjusted $^{\mathrm{a}}$ SHR $(95 \% \mathrm{Cl}$ \\
\hline 1 & - & - & - & - & - & - & 14.1 & 170 & 1 & 39 & 1 \\
\hline 2 & - & - & - & + & - & - & 9.6 & 114 & $1.15(0.90-1.48)$ & 33 & $1.46(0.91-2.35)$ \\
\hline 3 & - & - & + & - & - & - & 7.5 & 131 & $1.18(0.93-1.49)$ & 41 & $1.68(1.07-2.66)$ \\
\hline 4 & - & - & - & - & - & + & 6.8 & 177 & $1.42(1.14-1.77)$ & 58 & $1.57(1.03-2.39)$ \\
\hline 5 & - & - & + & - & - & + & 5.4 & 123 & $1.14(0.89-1.45)$ & 32 & $1.00(0.63-1.60)$ \\
\hline 6 & - & - & - & + & - & + & 4.5 & 68 & $1.14(0.85-1.52)$ & 25 & $1.61(0.96-2.69)$ \\
\hline 7 & - & + & - & - & - & - & 4.5 & 111 & $2.30(1.80-2.93)$ & 29 & $2.40(1.47-3.91)$ \\
\hline 8 & - & - & + & + & - & - & 4.4 & 85 & $1.47(1.13-1.91)$ & 30 & $2.22(1.39-3.54)$ \\
\hline 9 & - & + & + & - & - & + & 3.8 & 161 & $2.87(2.28-3.62)$ & 47 & $3.15(1.98-5.03)$ \\
\hline 10 & - & + & - & - & - & + & 3.6 & 124 & $2.19(1.72-2.8)$ & 38 & $2.31(1.43-3.74)$ \\
\hline 11 & - & + & + & - & - & - & 3.3 & 77 & $2.17(1.64-2.88)$ & 23 & $2.77(1.64-4.67)$ \\
\hline 12 & - & - & + & + & - & + & 3.2 & 83 & $1.56(1.19-2.04)$ & 35 & $2.69(1.59-4.20)$ \\
\hline
\end{tabular}

${ }^{a} H R$, Hazard ratio and $S H R$, subhazardratio: Adjusted for sex, educational attainment and marital status

public health interventions should target all risk factors, practically, an efficient approach might be an integrated chronic disease prevention strategy with a focus on subclusters, identified here, that are synergistic.

Both sleep duration and sleep quality have previously been related to mortality [38], work related disability [43], health care utilization and medication. Our data suggest that sleep should be a useful addition to include in a lifestyle risk index. Social relationships have also been shown to have powerful effects on health and survival $[25,27]$. New evidence indicates that the biophysiological mechanisms which underlie these links may involve altered immune functions [28] that can play a role in increased risk for many different chronic diseases. Our data are consistent with these findings. Significantly, both sleep and social participation are factors available for interventions at both the individual and the population level.

Risky alcohol consumption didn't appear among the top twelve combinations in our material. Alcohol consumption was relatively low in Norway in the 1990s, but has increased considerably the last decades [44]. In Australia, risky alcohol consumption had higher impact on mortality in a comparable study [16].

\section{Strengths and limitations}

The strength of this study is that the sample was from an unselected homogenous population in a defined geographical area in a northern European country. The validity of the main endpoint, i.e. death, is considered to be very accurate because of the high quality of national registries in Norway [45]. The response rate was relatively high, the sample size was satisfactory for most analyses, and follow-up time was sufficiently long.

Previous analyses from the HUNT Study have shown that those who declined to participate had somewhat lower socioeconomic status and slightly higher prevalence of chronic diseases and higher mortality than those who participated [46]. Further, we had to exclude a large number of participants because of missing values on at least one lifestyle risk factor. This could be particularly an issue for the current study because HUNT2 baseline measures were assessed through multiple questionnaires. A supplementary analysis comparing those with missing data on one or more risk factors by sex, age, education and marital status showed that older participants and those with lower education had higher rates of missing data than younger and more educated participants. Both of these variables have been included in the models, thereby providing model-based adjustment for the missing data [47]. Further, there is little reason to believe that this may have affected the association between lifestyle and mortality in this study significantly, as exposureoutcome associations based on internal comparisons are usually not dependent on the representativeness of the cohort [48]. The survey variables vary somewhat in quality and validity, especially for diet, where the question asked was limited, and therefore we probably have underestimated the importance of diet. Substituting zero for missing data on the PA measures constituting the physical inactivity risk factor may have biased downwards estimates of those sufficiently active. However, supplementary analyses excluding these observations $(n=5135)$ changed the effect size and direction of the mortality results only 
minimally and statistical significance not at all. Although the analyses showed a clear relationship between the risk factors and mortality with an incremental increase in risk with an increasing number of any of these risk factors, the small sample reporting six risk factors limits the reliability for that number. Only a small number of people in the youngest age group (20-35 years) died of CMD $(n=19)$. Therefore, these and all results would benefit from further validation in other cohorts.

\section{Future directions}

To refine this type of research, there is a need for better data on physical activity, more comprehensive data on diet and better characterization of other lifestyle behaviours. In the future, more objective measurements probably will become available for several types of behaviour, which can lead to more precise guides for public health efforts. A new wave of the HUNT Study (HUNT4) is being planned to be completed in 2017-2018. New objective measurements have high priority in this work.

\section{Conclusions}

Our data showed the effects of several traditional and emerging risk factors alone and in concert with others. Sleep duration, sitting time and social participation should be added to existing lifestyle indexes to predict all-cause and CMD mortality [4, 16, 27, 49]. Clinicians should pay attention to new components in "healthy lifestyles", but also be aware of the health services' limitations in terms of reducing all-cause and CMD mortality in the population because of the reliance on high-risk strategies targeting individuals [49]. Healthcare workers could contribute to the understanding of the potential of population-based prevention strategies in the society, to reduce detrimental social living conditions contributing to unhealthy sleep patterns, increasing everyday sitting time and barriers to social participation.

\section{Abbreviations}

CAGE: Cut-annoyed-guilty-eyeopener questionnaire; Cl: Confidence interval; CMD: Cardio-metabolic diseases; HR: Hazard ratio; HUNT: The Nord-Trøndelag Health Study; ICD: International classification of disease; IPAQ: International physical activity questionnaire; SHR: Subhazard ratio

\section{Acknowledgements}

The Nord-Trøndelag Health Study (The HUNT Study) is a collaboration between HUNT Research Centre (Faculty of Medicine, Norwegian University of Science and Technology NTNU), Nord-Trøndelag County Council, Central Norway Health Authority, and the Norwegian Institute of Public Health.

\section{Funding}

Ding Ding is funded by an Early Career Fellowship from National Health and Medical Research Council (APP1072223). The other co-authors received no external funding.

\section{Availability of data and materials}

The dataset supporting the conclusions of this article is available on appropriate request to the Data Accesses Committee at the HUNT Research
Centre. The dataset is not freely available due to privacy protection based on Norwegian law and the consent of the participants.

\section{Authors' contributions}

SK, DD and AB designed the study. SK, ERS, TLH and VR were involved in data acquisition. DD and AG performed the statistical analyses. All authors contributed to write and approved the final manuscript.

\section{Competing interests}

The authors declare that they have no competing interests.

\section{Consent for publication}

Not applicable.

\section{Ethics approval and consent to participate}

The HUNT2 Survey was performed in accordance with the Declaration of Helsinki, approved by the Data Inspectorate of Norway and approved by the Regional Committee for Medical Research Ethics [30]. All participants joined the study by signing a written consent. This study was also separately approved by the Regional Committee for Medical Research Ethics.

\section{Author details}

${ }^{1}$ HUNT Research Centre, Department of Public Health and General Practice, Norwegian University of Science and Technology, Forskningsveien 2, 7600 Levanger, Norway. ${ }^{2}$ Levanger Hospital, Nord-Trøndelag Hospital Trust, Levanger, Norway. ${ }^{3}$ Prevention Research Collaboration, Sydney School of Public Health, The University of Sydney, Camperdown, NSW, Australia. ${ }^{4}$ Centre for Chronic Disease Prevention, College of Public Health, Medical and Veterinary Sciences, James Cook University, Cairns, QLD, Australia.

Received: 18 April 2016 Accepted: 23 December 2016

Published online: 10 January 2017

\section{References}

1. World Health Organization. Global status report on noncommunicable diseases 2014. Geneva: World Health Organization; 2014

2. GBD 2013 Mortality and Causes of Death Collaborators. Global, regional, and national age-sex specific all-cause and cause-specific mortality for 240 causes of death, 1990-2013: a systematic analysis for the global burden of disease study 2013. Lancet. 2015;385:117-71.

3. Shankar A, McMunn A, Steptoe A. Health-related behaviors in older adults relationships with socioeconomic status. Am J Prev Med. 2010;38:39-46.

4. Ding D, Rogers $K$, van der Ploeg H, Stamatakis E, Bauman AE. Traditiona and emerging lifestyle risk behaviors and all-cause mortality in middle-aged and older adults: evidence from a large population-based Australian cohort. PLoS Med. 2015;12:e1001917.

5. Loef $\mathrm{M}$, Walach $\mathrm{H}$. The combined effects of healthy lifestyle behaviors on all cause mortality: a systematic review and meta-analysis. Prev Med. 2012; 55:163-70.

6. Prinelli F, Yannakoulia M, Anastasiou CA, Adorni F, Di Santo SG, Musicco M, et al. Mediterranean diet and other lifestyle factors in relation to 20-year allcause mortality: a cohort study in an Italian population. Br J Nutr. 2015;113: 1003-11.

7. Sasazuki S, Tsugane S. [Primary prevention of digestive tract cancer]. Nihon Shokakibyo Gakkai Zasshi. 2012;109:1133-8.

8. Odegaard AO, Koh WP, Yuan JM. Combined lifestyle factors and risk of incident colorectal cancer in a Chinese population. Cancer Prev Res (Phila). 2013:6:360-7.

9. Aleksandrova K, Pischon T, Jenab M, Bueno-de-Mesquita H, Fedirko V, Norat T, et al. Combined impact of healthy lifestyle factors on colorectal cancer: a large European cohort study. BMC Med. 2014;12:168.

10. Buckland G, Travier N, Huerta JM, Bueno-de-Mesquita HB, Siersema PD, Skeie $\mathrm{G}$, et al. Healthy lifestyle index and risk of gastric adenocarcinoma in the EPIC cohort study. Int J Cancer. 2015;137:598-606.

11. McKenzie F, Ferrari $P$, Freisling $H$, Chajes $V$, Rinaldi $S$, De BJ, et al. Healthy lifestyle and risk of breast cancer among postmenopausal women in the European prospective investigation into cancer and nutrition cohort study. Int J Cancer. 2015;136:2640-8.

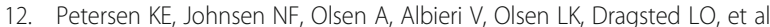
The combined impact of adherence to five lifestyle factors on all-cause, 
cancer and cardiovascular mortality: a prospective cohort study among Danish men and women. Br J Nutr. 2015;113:849-58.

13. Akesson A, Larsson SC, Discacciati A, Wolk A. Low-risk diet and lifestyle habits in the primary prevention of myocardial infarction in men: a population-based prospective cohort study. J Am Coll Cardiol. 2014;64:1299-306.

14. Hoevenaar-Blom MP, Spijkerman AM, Kromhout D, Verschuren WM. Sufficient sleep duration contributes to lower cardiovascular disease risk in addition to four traditional lifestyle factors: the MORGEN study. Eur J Prev Cardiol. 2014;21:1367-75.

15. Chomistek AK, Chiuve SE, Eliassen AH, Mukamal KJ, Willett WC, Rimm EB. Healthy lifestyle in the primordial prevention of cardiovascular disease among young women. J Am Coll Cardiol. 2015;65:43-51.

16. Ding D, Rogers K, Macniven R, Kamalesh V, Kritharides L, Chalmers J, et al. Revisiting lifestyle risk index assessment in a large Australian sample: should sedentary behavior and sleep be included as additional risk factors? Prev Med. 2014;60:102-6.

17. Long GH, Johansson I, Rolandsson O, Wennberg P, Fharm E, Weinehall L, et al. Healthy behaviours and 10-year incidence of diabetes: a population cohort study. Prev Med. 2015;71:121-7.

18. Chau JY, van der Ploeg HP, Merom D, Chey T, Bauman AE. Cross-sectional associations between occupational and leisure-time sitting, physical activity and obesity in working adults. Prev Med. 2012;54:195-200.

19. Edwardson CL, Gorely T, Davies MJ, Gray LJ, Khunti K, Wilmot EG, et al. Association of sedentary behaviour with metabolic syndrome: a metaanalysis. PLoS One. 2012;7:e34916.

20. Biswas A, Oh Pl, Faulkner GE, Bajaj RR, Silver MA, Mitchell MS, et al. Sedentary time and its association with risk for disease incidence, mortality, and hospitalization in adults: a systematic review and meta-analysis. Ann Intern Med. 2015;162:123-32.

21. Hall MH, Smagula SF, Boudreau RM, Ayonayon HN, Goldman SE, Harris TB, et al. Association between sleep duration and mortality is mediated by markers of inflammation and health in older adults: the health, aging and body composition study. Sleep. 2015;38:189-95.

22. Rod NH, Kumari M, Lange T, Kivimaki M, Shipley M, Ferrie J. The joint effec of sleep duration and disturbed sleep on cause-specific mortality: results from the Whitehall II cohort study. PLoS One. 2014;9:e91965.

23. Lee $H$, Kim S, Kim D. Effects of exercise with or without light exposure on sleep quality and hormone reponses. J Exerc Nutrition Biochem. 2014;18:293-9.

24. Kawachi I, Berkman LF. Social cohesion, social capital and health. In: Berkman LF, Kawachi I, editors. Social epidemiology. Oxford: Oxford University Press; 2000. p. 174-90.

25. Stringhini S, Berkman L, Dugravot A, Ferrie JE, Marmot M, Kivimaki M, et al. Socioeconomic status, structural and functional measures of social support, and mortality: the British Whitehall II cohort study, 1985-2009. Am J Epidemiol. 2012;175:1275-83.

26. Hyyppa MT, Maki J. Social participation and health in a community rich in stock of social capital. Health Educ Res. 2003;18:770-9.

27. Cacioppo JT, Cacioppo S. Social relationships and health: the toxic effects of perceived social isolation. Soc Personal Psychol Compass. 2014;8:58-72.

28. Yang YC, Schorpp K, Harris KM. Social support, social strain and inflammation: evidence from a national longitudinal study of U.S. adults. Soc Sci Med. 2014;107:124-35.

29. Krokstad S, Langhammer A, Hveem K, Holmen T, Midthjell K, Stene T, et al. Cohort profile: the HUNT study, Norway. Int J Epidemiol. 2013;42:968-77.

30. Holmen J, Midthjell $K$, Krüger $\varnothing$, Langhammer A, Holmen TL, Bratberg GH, et al. The Nord-Trøndelag Health Study 1995-97 (HUNT 2): objectives, contents, methods and participation. Norsk Epidemiologi. 2003;13:19-32.

31. Ewing JA. Detecting alcoholism. The CAGE questionnaire. JAMA. 1984;252: 1905-7.

32. Dhalla S, Kopec JA. The CAGE questionnaire for alcohol misuse: a review of reliability and validity studies. Clin Invest Med. 2007;30:33-41.

33. Kurtze N, Rangul V, Hustvedt BE, Flanders WD. Reliability and validity of self-reported physical activity in the Nord-Trondelag Health Study (HUNT 2). Eur J Epidemiol. 2007;22:379-87.

34. Craig CL, Marshall AL, Sjostrom M, Bauman AE, Booth ML, Ainsworth BE, et al. International physical activity questionnaire: 12-country reliability and validity. Med Sci Sports Exerc. 2003;35:1381-95.

35. Ernstsen L, Rangul V, Nauman J, Nes BM, Dalen H, Krokstad S, et al. Protective effect of regular physical activity on depression after myocardial infarction: the HUNT study. Am J Med. 2016:129:82-8.
36. Chau JY, Grunseit AC, Chey T, Stamatakis E, Brown WJ, Matthews CE, et al. Daily sitting time and all-cause mortality: a meta-analysis. PLoS One. 2013;8:e80000.

37. Cappuccio FP, Cooper D, D'Elia L, Strazzullo P, Miller MA. Sleep duration predicts cardiovascular outcomes: a systematic review and meta-analysis of prospective studies. Eur Heart J. 2011;32:1484-92.

38. Cappuccio FP, D’Elia L, Strazzullo P, Miller MA. Sleep duration and all-cause mortality: a systematic review and meta-analysis of prospective studies. Sleep. 2010;33:585-92.

39. Bygren LO, Konlaan BB, Johansson SE. Attendance at cultural events, reading books or periodicals, and making music or singing in a choir as determinants for survival: Swedish interview survey of living conditions. BMJ. 1996;313:1577-80.

40. Thiebaut ACM, Benichou J. Choice of time-scale in Cox's model analysis of epidemiologic cohort data: a simulation study. Stat Med. 2004;23:3803-20.

41. Fine JP, Gray RJ. A proportional hazards model for the subdistribution of a competing risk. J Am Stat Assoc. 1999;94:496-509.

42. Walter SD. The estimation and interpretation of attributable risk in health research. Biometrics. 1976;32:829-49.

43. Sivertsen B, Overland S, Neckelmann D, Glozier N, Krokstad S, Pallesen S, et al. The long-term effect of insomnia on work disability: the HUNT-2 historical cohort study. Am J Epidemiol. 2006;163:1018-24.

44. Rossow I, Makela P, Kerr W. The collectivity of changes in alcohol consumption revisited. Addiction. 2014;109:1447-55.

45. Bakken IJ, Ellingsen CL, Pedersen AG, Leistad L, Kinge JM, Ebbing M, et al. Comparison of data from the cause of death registry and the Norwegian patient register. Tidsskr Nor Laegeforen. 2015;135:1949-53.

46. Langhammer A, Krokstad S, Romundstad P, Heggland J, Holmen J. The HUNT study: participation is associated with survival and depends on socioeconomic status, diseases and symptoms. BMC Med Res Methodol. 2012;12:143.

47. Collins LM, Schafer JL, Kam CM. A comparison of inclusive and restrictive strategies in modern missing data procedures. Psychol Methods. 2001;6: 330-51.

48. Mealing NM, Banks E, Jorm LR, Steel DG, Clements MS, Rogers KD Investigation of relative risk estimates from studies of the same population with contrasting response rates and designs. BMC Med Res Methodol. 2010;10:26.

49. Rose G. The strategy of preventive medicine. Oxford: Oxford University Press; 1992.

\section{Submit your next manuscript to BioMed Central and we will help you at every step:}

- We accept pre-submission inquiries

- Our selector tool helps you to find the most relevant journal

- We provide round the clock customer support

- Convenient online submission

- Thorough peer review

- Inclusion in PubMed and all major indexing services

- Maximum visibility for your research

Submit your manuscript at www.biomedcentral.com/submit 